\title{
Energy Efficiency and Rebound Effect: Does Energy Efficiency Save Energy?
}

\author{
Abdulkadir Buluş ${ }^{1}$, Nurgün Topalli ${ }^{2}$ \\ ${ }^{1}$ Faculty of Economics and Administrative Science, Selçuk University, Konya, Turkey \\ ${ }^{2}$ Faculty of Economics and Administrative Science, Bozok University, Yozgat, Turkey \\ E-mail:akbulus@selcuk.edu.tr,topallinurgun@hotmail.com \\ Received February 9, 2011; revised March 18, 2011; accepted April 5, 2011
}

\begin{abstract}
The aim of this study is to examine the theoric and empirical literature about "rebound effect". This study summarizes energy efficiency policy and programs in general and in Turkey. Also it gives defination of the "rebound effect" concept. The rebound effect is related to consumer's tendency to consume more energy due to economic benefit from efficiency improvement. The "rebound effect" is the focus of a long-running dispute of energy economics but it is very new concept in the most developing countries. In literature according to some economist gains in energy efficiency will also reduce the real per unit price of energy services and hence the consumption of energy will rise and partially offset the initial reduction in the usage of energy sources. However for others size of the rebound effect is too small to take attention. The empirical literature shows that the size of rebound effect can change from country to country and sector to sector.
\end{abstract}

Keywords: Energy, Energy Efficiency, Rebound Effect, Energy Economics

\section{Introduction}

The energy issue has been crucially important for state economies, and (surely) it will sustain its importance in the future. Besides being a basic input for economies, energy is the determinant for the world economy in the fields of economical, social and geographical environment. Acquiring sufficient energy economically, safely and cleanly in a determined time is an important sign for countries to show their levels of development. The shocks experienced in energy prices in 1970s and the real wage fluctuations profoundly influenced state economies in some ways. One of these influences has been observed in using new technologies in order to minimize the energy input used in production process. The relation between energy efficiency and energy consumption has been a matter of several discussions among developed countries since 1980s. Brookes (1979), Khazzoom (1980), Saunders (1984, 1992), Schurr (1982) assert that; while the increases in energy efficiency at micro level causes decrease in energy consumption at micro level, it will cause an increase in energy consumption at national or macro levels [1-5]. This approach is named as Khazzoom-Brookes postulate. This thesis was first used (proved) by Harry Saunders in 1992. The studies related to this field were considerably influenced by the Jevons' study named "The Coal Question" [6].

Our study consists of three parts. In the first part, energy efficiency and policy is discussed. Second part comprises the definitons of rebound effect and related literature. Consequently, in the final part different policies are introduced that comprise the energy issues.

\section{Energy Efficiency}

Energy efficiency is closely related to the energy safety. Reducing the energy intensity at ultimate consumption, transmission and distribution losses, and employing technologies which increase productivity are among the efficiency increasing links of energy chain. The energy efficiency and increasing its efficiency have a significant effect on the solution of some issues such as high external dependency rate, energy safety, unemployment, leading in technology and climate change $[7,8]$. In the Energy Efficiency Issue numbered 5627, Energy efficiency is defined as "diminishing energy consuption without causing a decrease in life standarts and service quality in domiciles and a decrease in production quality and amount in industries" [9]. Today, the main aim of the energy efficiency policies is not only the matter of in- 
creasing the energy consumption per capita. It is the aim of setting up a system which enables maximum energy generation, distribution and consumption with using minimum energy instead. These policies comprise several steps such as, house designing, standardizing the electrical appliances used at home and in industry, improving consumer awareness, and tax and incentive programs [10].

\subsection{Energy Efficiency Policy and Programs}

Energy efficiency has some positive benefits for states, energy consumers and enviroment around the world. By using energy efficiency programs countries can protect their natural resource's and environment, reduce dependence on fossil fuels and increase energy security [11]. Last two decades goverments perform end-use energy efficiency facility besides supply-side facility. Enduse efficiency implication policy and programs are demand-side management, energy conservation centers, standarts and labeling, commercial building codes, special funds, credit lines and loan guarantee programs, market transformations, information programs, reporting and benchmarking [11-13]. Also governments use various policy tools to improve energy efficiency. Some of them are energy and carbon taxes, investment subsides and public incentives, emission trades, voluntary agreements, R \& D subsides [14].

Though energy efficiency has many economic and environment gains, there are some barriers in efficiency investments and in the markets. Energy efficiency barriers are summarized as technical barriers, economic barriers, information barriers, host-rental barriers [14] lack of access to information, limited access to capital, lack of responsibility, lack of rational decision-making inappropriate price signals, lack of access to and trust in efficiency equipment [15]. Governments can implicate more than one programs at the same time to achieve energy efficiency goals.

\subsection{Energy Efficiency Policies in Turkey}

In Turkey, Energy Efficiency Law and the Regulation on Increasing Efficiency in the use of Energy Sources and Energy came into force in 2007 and 2008 to reduce external dependency, use energy effectively, prevent wastage, reduce energy costs and to protect the environ ment. Circular No. 2008/2 dated 15/02/2008 from the Office of the Prime Minister defined measures for the effective and efficient use of energy within public bodies and institutions. In 2008, "National Energy Efficiency Movement" started and year 2008 was announced as the "Energy Efficiency Year" [16]. The Energy Efficiency Law
No. 5627, which was accepted in 2007, was to use energy effectively, prevent wastage, relieve the burden of energy costs on economy and to increase efficiency in the use of energy sources and energy itself to protect the environment [9]. Among the measures that are taken by the Ministry of Energy and National Sources, priority is given to the replacement of incandescent bulbs used for lighting purposes with compact fluorescent lamps which are up to 5 times more energy-efficient. Another implementation to increase energy efficiency is to start "E1 Ele ENVER" movement as a step of "National Energy Efficiency Movement". In this context, at primary schools, awareness-raising activities about energy efficiency were carried and dispensing of energy-efficient lamps started [16].

\section{The Concept of Rebound Effect}

Rebound effect is a long-term discussed issue on energy economy. Main discussion topic is whether reductions in energy consumption as a result of technical efficiency improvements in the use of energy can be calculated by simple engineering calculations or not. For example, are the improvements provided a $20 \%$ thermal efficiency in the heating system going to lead to a $20 \%$ reduction also in aggregate energy consumption. According to economic theory, this will not happen. Because these energy savings can be offset by various mechanisms [17,18]. Rebound effect was first observed in 1965 by Stanley Jevons. Jevons observed that the new efficient steam engine reduced the coal consumption and this reduction in consumption lowered the prices of coal. This means not only providing more people access to coal, but also coal becomes more economically for new uses and coal consumption rises in large amounts [19]. Rebound effect is associated with consumers' tend to consume more energy due to economic gains of efficiency improvements. For example, when the fuel cost per kilometer falls with fuel-efficient car, the distance can be made more per kilometer with gas. In general, price reductions will cause the rise in consumption. Expected energy saving can be lost because of people's tend to increase consumption of energy services due to falling prices. This missing part is expressed as the rebound effect [20].

At the micro level, the main question is whether technical efficiency improvements in energy use for reducing consumption can be estimated by simple engineering calculations. For example, is $20 \%$ improvement in the fuel efficiency of passenger cars going to reduce engine-fuel consumption by $20 \%$ in the use of personal cars. According to economic theory, this result can not be obtained. Because, energy efficiency improvements lower marginal cost of energy services and can lead to a rise in 
the consumption of travel and energy services. For example, when the cost of driving per mile is cheaper, consumers can choose to drive more and drive longer distances. A rise in the consumption of these energy services can offset the expected reduction in energy consumption or savings obtained from fuel efficient cars can be turned to other energy intensive goods and services such as overseas flights by drivers. Similarly, any reducetion in the energy demand will turn into lower energy prices and this will be able to stimulate the increase of energy consumption [18]. Energy efficiency will result in higher energy consumption; this case was named by Harry Saunders (1992) as "Khazzom-Brookes Postulate". Because this question was firstly discussed by Len Brookes (1979) and Daniel Khazzoom (1980). According to Khazzoom (1980), with regard to household tools, under the assumption of a positive demand elasticity of demand "a decrease occurs in the effective prices of goods, the demand does not remain constant as a result of lower effective prices and tends to increase" [1].

\subsection{Classification of Rebound Effect}

Rebound effect most simply consists of direct, indirect and economy-wide effects and is measured as a difference between planned and actual savings because of the efficiency improvements [19].

\subsubsection{Direct Rebound Effect}

Direct rebound effect is associated with individual energy services such as heating, lighting and cooling. The provision of these services requires the provision of energy. The development of energy efficiency in a certain energy service will reduce the price of that service and may lead to an increase in the consumption of service. Therefore, the decrease, expected to become as a result of efficiency improvements, in energy consumption will be balanced. For consumers, direct rebound effect can be divided into two as the substitution and income elasticity. For producers, direct rebound effect can be classified as the substitution and output effect $[19,21]$.

\subsubsection{Indirect Rebound Effect}

In an economy, even if direct rebound effect is zero in particular energy services, there are other factors that are in the direction to be lower than the expected value obtained from simple calculations of economy-wide reducetion in energy consumption. For example, money savings provided from engine fuel consumption may lead to other goods and services which have energy requirements. This effect is called indirect rebound effect. It will be useful to classify the indirect rebound effect as "process (embodied) energy" and "secondary effect (seconddary)". The aggregate of direct and indirect rebound effect is defined as economy-wide rebound effect. The classification of rebound effect is given in Table 1 [18].

\subsection{Measuring the Rebound Effect}

A part of debates about the size of rebound effect is due to the lack of clear definitions for rebound effect. Energy efficiency can be measured in different ways like physiccal indicators or economic indicators (energy per output unit). Energy efficiency can be measured at different levels in individual production process, in a factory, in a company, in a sector, even in economy in general. For this reason, rebound effect is dependent on the selected indicators and levels [18]. Rebound effect can be expressed with a simple equation as follows [22]:

$$
\begin{aligned}
& \text { Rebound Effect }=100 \% \\
& \text {. Calculated Savings }(\mathrm{kWh})-\text { Actual Savings }(\mathrm{kWh}) \\
& \text { Calculated Savings }(\mathrm{kWh})
\end{aligned}
$$

As partial, while 0 rebound effect means a complete success for reducing energy use targets, $100 \%$ rebound effect means a complete failure [20]. It is possible to collect the methods used to obtain the rebound effect in five groups. The first two methods are related with direct rebound effect. Other methods are related with economy wide rebound effect. These methods are evaluation studies, econometric studies, substitution elasticity studies, computable general equilibrium models, energy, efficiency and economic growth studies.

\subsection{Applied Literature Related to the Rebound Effect}

\begin{tabular}{|c|c|c|c|}
\hline \multirow{3}{*}{$\begin{array}{l}\text { "Engineering" } \\
\text { Estimates of energy savings }\end{array}$} & \multicolumn{3}{|c|}{ Actual energy savings } \\
\hline & Fconomy-wide rehound effect & Direct rebound effect & $\begin{array}{l}\text { Substitution effect } \\
\text { Income/output effect }\end{array}$ \\
\hline & & Indirect rebound effect & $\begin{array}{l}\text { Embodied energy } \\
\text { Secondary effect }\end{array}$ \\
\hline
\end{tabular}

According to some researchers (Lovins et al., 1998;

Table 1. The classification of rebound effect. 
Shipper and Grubb, 2000), the importance of rebound effect in energy services is small because the demand for such services is inelastic in many examples and energy has a smaller share in the total cost of these services. Another group (Brookes, 2000; Herring, 2006) indicates that rebound effect is important enough to balance the energy savings provided from energy efficiency improvements [18]. In Lovin (1998), it is suggested that "rebound" or "takeback" effect is at the low level in energy efficiency gains by consumers. But for Khazzoom, Lovin's analysis is wrong as he does not take into account in his analysis the macroeconomic responses of changes in energy prices which are caused by improvements in energy efficiency [6]. As a result of evaluation studies related to U.S. infrastructure, Nadel (1993) found that direct rebound effect is $10 \%$ or less in lighting systems, it is zero for heating water and meaningless for cooling systems. Also, according to the evaluation studies, standard engineering models estimate the energy savings in energy efficiency improvements more than twice in home heating systems. As a result of study it is found that direct rebound effect is less than $30 \%$ in heating services [18].

According to Gottron (2009), this phenomenon occured only in very special examples, in some developing countries, in coal markets of mid-1800s or in electricity markets of early 1900s. Generally, real rebound effect is accepted to be limited in mature markets. Actual rebound effect depends on various variables such as significant resources, significant regulations, how supply market improves and the general state of the economy. Actual rebound effect measurements were found between 0 and $40 \%$ for ultimate power tools. For example, a measurable rebound effect was not found in activity rises in domestic appliances (white goods). However, the rebound effect encountered in area heatings and cooling units ranges from $0 \%$ to $50 \%$. At the same time, rising rebound effect in automobile fuel economy has been the subject of many studies. The rebound effect in this sector was found to range generally between $10 \%$ and $30 \%$ [19].

Sorrell (2007), it was found that in OECD countries, direct rebound effect is less than $30 \%$ in individual home heating, home cooling and personal automobile transportation, but for transportation rebound effect is nearly $10 \%$. Direct rebound effect is expected to fall in the future due to satisfication experienced in demand for these energy services. In studies based on econometric studies, it was found that in developed countries, direct rebound effect is strong in automobile, transportation and home heating systems, but it is weaker for other consumer energy services. While theoretical discussions indicate that direct rebound effect will be higher in developing countries than developed countries, in practice energy effi- ciency improvements in developing countries are weak in certain ways [18].

In Schipper and Grubb (2000), rebound effect was tried to be determined by taking energy use, energy efficiency and price variables in different sectors in IEA countries into acount. The date of 1970 was choosen as the beginning period of the study. It was identified that basic measurements in activities (car use, output of manufacturing industry, structure, home field, etc.) in the period under review show a little change to the changes in energy prices and efficiency. Also, in the study, indirect effects were found to be very small in the periods of 1970 and 1980 [23]. In Grepperud ve Rasmussen (2004), rebound effect for Norway economy was investigated by using general equilibrium model. Energy efficiency improvements experienced in the electricity and oil in 6 different sectors were examined in the study. As a result of study, different and meaningful findings were obtained between sectors both in energy use and in the formation of greenhouse gases. It was found that, there is a meaningful rebound effect in manufacturing sector, electricity consumption will increase by $87.5 \%$ and electricity consumption will increase $17.5 \%$. In other sectors, rebound effect is very weak or absent [24].

In Bentzen (2004), potential rebound effect in manufacturing industry was tried to be estimated by using time series data of US 1949-1999 period. Dynamic OLS method was used in the study. In the context of asymmetric price effects that the model enables, rebound effect was found to be nearly $24 \%$ for US manufacturing sector. When compared with other empirical studies which applied to firms, this result was found to be high. The reason for this is, structural changes that affect energy consumption and aggregated data used are probably effective. Therefore, it is stated that rebound effect can be lower than $24 \%$ of its actual value [25]. In Berkhout et al. (2000), price elacticities obtained by empirical estimates were used for Holland as indication of rebound effect and as a result, this effect was found to be between 0 and $30 \%$. These results show that an important energy saving potential is obtained from new technologies. But for consumers, saving potential remains neutral-ineffective in some levels due to increasing demand for energy services [26].

\section{Conclusions}

In 1980s, some views were put forward in the literature that energy efficient studies will not reduce the energy consumption, even they will increase it. The concept that increases in savings provided with energy efficient practises will be balanced with the increases in energy consumption is called as rebound effect. Many governments 
search ways for improving energy efficiency in the economy to reduce the dependency on fosil fuels like oil, natural gas, coal and to reach the target of reducing carbon emissions with environmentally friendly practices. Some mechanism that get together usually under the rebound effect can reduce the size of targets in "energy savings". There are some evidences showing distinct types of energy efficient technologies caused an increase in energy demand in the past. This case was seen in the nineteenth century especially in new technologies like steam engine. There are few studies about the improvements in energy efficiency in developing countries. Rebound effect will probably be higher in developing countries. Because, the demand for energy services in these countries is far from sauration and this case is supported by a limited number of empirical studies. Both direct and indirect rebound effect can emerge with quite different results between different technologies, sectors and income groups.

Recently studies are focused on the impact of rebound effect on fossil markets as gasoline markets and global climate change. Energy efficiency can be encouraged with policies such as increasing energy prices, carbon taxes and building regulations. Each of these policies has an important role on energy and climate policies. But, some applications related with these policies can increase energy consumption and non-price policies for reducing carbon emissions. In some circumstances, for example in the presence of energy-efficient technologies that improve significantly the efficiency of energy-intensive industries, rebound effect can go beyond $50 \%$ in economy in general and it can increase the energy consumption in the long term. This put forth the need for reevaluating the potential energy efficiency policies. In sectors that rebound effect is expected to be high, there may be need for energy policies which will increase energy prices. Policy makers will be able to obtain real achievements from planned efficiency policies by calculating the rebound effect and they will be able to revise their programs by taking the possible rebound effect into account. Losses in energy savings due to rebound effect are closely related to losses in consumers' quality of life. Therefore, rebound effect is an issue which must be considered.

\section{References}

[1] L. Brookes, "A Low-Energy Strategy for the UK by G. Leach et al.: A Review and Reply," Atom, Vol. 269, 1979, pp. 3-8.

[2] J. D. Khazzoom, "Economic Implications of Mandated Efficiency Standars for Household Appliances," Energy Journal, Vol. 1, No. 4, 1980, pp. 85-89.

[3] H. Saunders, "The Macrodynamics of Energy Shocks,
Short Run and Long Run," Energy Economics, Vol. 6, No. 1, 1984, pp. 21-34. doi:10.1016/0140-9883(84)90040-9

[4] H. Saunders, "The Khazzoom-Brookes Postulate and Neoclassic Growth," Energy Journal, Vol. 13, No. 4, 1992, pp. 131-148. doi:10.5547/ISSN0195-6574-EJ-Vol13-No4-7

[5] S. Schurr, "Energy Conservation and Productive Efficiency: Some Thoughts Based on American Experience," Energy Journal, Vol. 3, No. 3, 1984, pp. 3-14.

[6] H. Herring, "Does Energy Efficiency Save Energy? The Debate and Its Conseguence," Applied Energy, Vol. 63, No. 3, 1999, pp. 209-213. doi:10.1016/S0306-2619(99)00030-6

[7] Ö. Selvitop, “Türkiye'nin Enerji Politikalarına Genel Bakış,” 2007. http://www.emo.org.tr/ekler/f44ebfabbb70378.ek.pdf

[8] T. Keskin, "Avrupa Birliği'nde ve Türkiye'de Enerji Verimliliğinin Enerji Sektöründe Beklenen Etkileri," Enerji Kongresi, 2006.

http://enerji2023.org/index.php?option=com_content\&vie $\mathrm{w}=$ article\&id=101:enerjvermll\&catid=7:goerueler\&Itemi $\mathrm{d}=18$

[9] “Enerji Verimliliği Kanunu,” Resmi Gazete Sayı, 2007. http://mevzuat.dpt.gov.tr/kanun/5627.htm

[10] N. Pamir, "Dünyada ve Türkiye'de Enerji, Türkiye'nin Enerji Kaynakları ve Enerji Politikaları,” 2003. http://www.metalurji.org.tr/dergi/dergi134/d134_73100.pdf

[11] A. Sarkar and J. Singh, "Financing Energy Efficiency in Developing Countries-Lessons Learned and Remaining Challenges," Energy Policy, Vol. 38, No. 10, 2010, pp. 5560-5571. doi:10.1016/j.enpol.2010.05.001

[12] T. Oliver, D. Lew, R. Redlinger and C. Prijanonda, "Global Energy Efficiency and Renewable Energy Policy Options and Initiatives," Energy for Sustainable Development, Vol 5, No. 2, 2001, pp. 15-25. doi:10.1016/S0973-0826(08)60266-5

[13] E. Worrell and L. Price, "Barriers and Opportunities: A Review of Selected Successfull Energy-Efficiency Program," Proceedings 2001 Industrial Energy Technology Conference, Houston, 1-4 May 2001, pp. 65-74.

[14] K. Blok, "Introduction to Energy Analysis," Techne Press, Amsterdam, 2007.

[15] T. Woolf and E. D. Lutz, "Energy Efficiency in Britain Creating Profitable Alternatives," Utulities Policy, Vol. 3, No. 3, 1993, pp. 233-242.

[16] Enerji ve Tabii Kaynaklar Bakanlığı, 2009. http://www.enerji.gov.tr/index.php?dil=tr\&sf=webpages $\& b=$ enerjiverimliligi $\& b n=217 \& \mathrm{hn}=\& \mathrm{id}=587$

[17] S. Sorrell and J. Dimitropoulo, "The Rebound Effect: Microeconomic Definitions, Extensions and Limitation," Ecological Economics, Vol. 65, No. 3, 2008, pp. 636-649.

[18] S. Sorrell, "The Rebound Effect: An Assessment of the Evidence for Economy-Wide Energy Savings from Improved Energy Efficiency," Engineering, Vol. 35, 2007, pp. 5622-5629. doi:10.1016/j.enpol.2007.05.028

[19] F. Gottron, "Energy Efficiency and the Rebound Effect: Does Increasing Efficiency Decrease Demand," CRS 
Report for Congrees, RS20981, 2000, pp. 1-4.

[20] S.-H. Jin, "The Effectiveness of Energy Efficiency Improvement in a Developing Country: Rebound Effect of Residential Electricity Use in South Korea," Energy Policy, Vol. 35, No. 11, 2007, pp. 5622-5629. doi:10.1016/j.enpol.2007.05.028

[21] L.A. Greening, D. L. Greene and C. Difiglio, "Energy Efficiency and Consumption-The Rebound Effect-A survey," Energy Policy, Vol. 28, No. 6-7, 2000, 389-401. doi:10.1016/S0301-4215(00)00021-5

[22] R. Hass and P. Biermayr, "The Rebound Effect for Space Heating-Empirical Evidence from Austria," Energy Policy, Vol. 28, No. 6-7, 2000, pp. 403-410. doi:10.1016/S0301-4215(00)00023-9

[23] L. Schipper and M. Grubb, "On the Rebound? Feedback between Energy Intensities and Energy Uses in IEA Countries," Energy Policy, Vol. 28, No. 6, 2000, pp. 367-388. doi:10.1016/S0301-4215(00)00018-5

[24] S. Grepperud and I. Rasmussen. " A General Equilibrium Assessment of Rebound Effects," Energy Economics, Vol. 26, No. 2, 2004, pp. 261-282. doi:10.1016/j.eneco.2003.11.003

[25] J. Bentzen, "Estimating the Rebound Effect in US Manufacturing Energy Consumpion," Energy Economics, Vol. 26, No. 1, 2004, pp. 123-134. doi:10.1016/S0140-9883(03)00047-1

[26] P. H. G. Berkhout, J. C. Muskens and J. W. Velthujsen, "Defining the Rebound Effect," Energy Policy, Vol. 28, No. 6-7, 2008, pp. 425-432. doi:10.1016/S0301-4215(00)00022-7 